\title{
A Method for Recovery of N-methyl 2-pyrrolidone from Wastes of Solvent Regeneration Unit in 1,3-Butadiene Extraction Plant
}

\author{
H. R. Mortaheb, A. Bolhasani, F. Meshkini, F. Ghaemmaghami, and K. Tabar Heidar
}

\begin{abstract}
N-methyl 2-pyrrolidone (NMP) is applied as a solvent in 1,3-butadiene (BD) extraction plants. The solvent, which is circulated through the unit, is regenerated in a solvent recovery unit. The wastes of solvent recovery unit contains at least $50 \mathrm{wt} \% \mathrm{NMP}$ which is generally disposed. The recovery of NMP from this waste for reusing in the BD purification plant was studied in the present research by experimental methods such as dissolution, coagulation, and distillation. A purified NMP with the concentration of $99 \mathrm{wt} \%$ could be obtained. In addition, the process was scaled up for manufacturing and installing in the BD extraction plant.
\end{abstract}

Index Terms-NMP, solvent recovery, BD extraction plant, dissolution, coagulation, distillation.

\section{INTRODUCTION}

1,3-butadiene (normal boiling point: $-4.4^{\circ} \mathrm{C}$, liquid density at $20^{\circ} \mathrm{C}: 611 \mathrm{~kg} / \mathrm{m}^{3}$ ) is a colorless, non-corrosive gas with mild aromatic or gasoline-like odor [1]. It is accounted a major product in petrochemical industry and an important feedstock as a co-monomer in the production of rubbers and plastics such as styrene butadiene rubber, polybutadiene rubber, and styrene butadiene latex [2]. 1,3-Butadiene, which is a major fraction of $\mathrm{C} 4$ mixtures as the by-product of naphtha cracker units, should be purified before using in the polymerization processes. In general, $\mathrm{C} 4$ mixtures include butanes, butenes, 1,2-butadiene, 1,3-butadiene and acetylenes, etc. Due to formation of several azeotropes, very close boiling points and low relative volatilities of these components, the separation of 1,3-butadiene from $\mathrm{C} 4$-cut is not possible by conventional distillation [3]. The separation is then performed by extractive distillation, in which a miscible, high boiling, and relatively nonvolatile solvent is used having no azeotrope with the other components in the mixture. Interactions of solvent with the components of original mixture lead to alter their relative volatilities [4]. The C4 components in the feed have distinct solubilities compared to 1,3-butadiene in some solvents such as acetonitrile (ACN) [5], dimethyl formamide (DMF) [5], [6], and n-methyl-2-pyrrolidone (NMP) [7].

The consumption of ACN and DMF is restricted due to the

Manuscript received January 19, 2016; revised March 13, 2016.

H. R. Mortaheb, F. Meshkini, F. Ghaemmaghami, and K. Tabar Heidar are with the Chemistry \& Chemical Engineering Research Center of Iran, Tehran, Iran (e-mail: mortaheb@ccerci.ac.ir, meshkini@ccerci.ac.ir, ghaemmaghami@ccerci.ac.ir, ktabarh@ccerci.ac.ir).

A. Bolhasani is with the Research and Development, Jam Petrochemical Co., Assaluyeh, Boushehr, Iran (e-mail: a_bolhasani@jpcomplex.com). toxicity of $\mathrm{ACN}$ and hydrolysis potential of DMF into corrosive formic acid during the distillation process [6], [8]. The ideal properties such as high selectivity, low vapor pressure, stability, and proper solubility for acetylenes make NMP a superior solvent for BD purification [9], [10]. In addition, it has been reported that 1,3-butadiene extraction process using NMP can reduce the initial equipment cost and heat duty because of lower operating pressure and temperature [11]-[13].

Butadiene unit in Jam petrochemical company located in Asaluyeh region produces annually over 100,000 metric ton of BD using NMP as the solvent. The circulated solvent is regenerated in a solvent recovery unit. The drained waste from the solvent regeneration unit is a viscous liquid and contains at least $50 \mathrm{wt} \%$ NMP. Since 65-90 ton of fresh NMP is used yearly as the make-up in the BD plant, any effort to recover NMP from the waste can significantly reduce the consumption of fresh solvent in the BD extraction plant [14]. The current research aims to recover NMP content in the waste of the solvent recovery unit.

\section{EXPERIMENTAL}

The feed used in the experiments was sampled from bottom of the regeneration unit. Analyzing the feed by HPLC reveals a content of 45 to $85 \mathrm{wt} \%$ depending on the operating pressure of the regeneration unit. The sample used in the rest of experiments has a NMP content of $46.7 \mathrm{wt} \%$ (Fig. 1a) with a dark color and high viscosity.

\section{A. Dissolution}

Solvents such as butanol, octanol, n-heptane, and water were applied for dissolution of NMP feed. The solvent to feed proportion was kept constant in a ratio of 2:1 for all the experiments. The mixtures were filtered in order to separate the undissolved part after stirring for about $3 \mathrm{~h}$. The effects of dissolution parameters such as the number of stages and temperature on dissolution efficiency were investigated. NMP dissolution efficiency, $\eta_{\mathrm{N}}$, and total dissolution efficiency, $\eta_{\mathrm{T}}$, are calculated by following equations:

$$
\begin{gathered}
\eta_{\mathrm{N}}=\frac{(\mathrm{NMP} \text { conc. })_{\text {filterate }}[\mathrm{wt} \%] \times \text { filtrate weight }[\mathrm{g}]}{(\mathrm{NMP} \text { conc. })_{\text {sample }}[\mathrm{wt} \%] \times \text { sample weight }[\mathrm{g}]} \times 100 \\
\eta_{\mathrm{T}}=\frac{\text { filtrate weight }[\mathrm{g}]}{\text { sample weight }[\mathrm{g}]} \times 100
\end{gathered}
$$

\section{B. Coagulation}

The coagulation experiments were performed using some 
coagulants such as $\mathrm{CaCl}_{2}, \quad \mathrm{Al}(\mathrm{OH})_{3}, \quad \mathrm{Ca}(\mathrm{OH})_{2}, \quad$ and Polyacrylamide (PAM) with a constant loading of $2 \mathrm{wt} \%$. The process was conducted for 2 min at stirring speed of 200 $\mathrm{rpm}$, and for $5 \mathrm{~min}$ at stirring speed of $20 \mathrm{rpm}$. The formed flocs were allowed to settle for $30 \mathrm{~min}$ and then separated from the solution by filtration [15]. Then the filtrates were analyzed by HPLC.

\section{Distillation}

Distillation process was applied for separation of solvent from NMP. The operating pressure of the process i.e. atmospheric or vacuum was selected according to volatilities of the sample components.

\section{Analysis}

High performance liquid chromatography (HPLC) technique was applied for analysis of the samples to determine the NMP concentration. The HPLC equipment (SCL-8A/LC-8A/FCV-100B/SPD-6AV, Shimadzu) was provided with a Nucleosil-100-5-C18 column $(250 \times 4.0 \mathrm{~mm}+5 \times 4.0 \mathrm{~mm})$ employing UV detector at wavelength of $214 \mathrm{~nm} \mathrm{[16].} \mathrm{A} \mathrm{solution} \mathrm{of} \mathrm{water} \mathrm{and}$ acetonitrile (40:60) was used as the mobile phase and the flow rate was controlled at $1.0 \mathrm{ml} / \mathrm{min}$. The retention time of NMP is $3.3 \mathrm{~min}$ at these conditions.

\section{RESULTS AND DISCUSSION}

\section{A. Dissolution Tests}

Among the solvents tested in the dissolution experiments, butanol and octanol were found to be improper due to nearly total dissolution of the feed and lack of selectivity for NMP. Their total and NMP dissolution efficiencies are listed in Table I.

n-Heptane as a non-polar solvent was applied in the dissolution test at ambient temperature. The total dissolution efficiency of feed in the n-heptane was determined as $22 \mathrm{wt} \%$. The chromatograms of feed and dissolute filtrate are shown in Fig. 1. As it can be seen in Fig. 1(b), the solute is mainly consisted of NMP with minor other impurities. This shows a good selectivity of n-heptane for NMP with low extraction efficiency. In order to improve the efficiency of NMP extraction, the number of dissolution stages and temperature were altered and their effects were investigated. The results are shown in Table I.

As the solubility of NMP in n-heptane is increased by temperature [17], the dissolution was performed at $100^{\circ} \mathrm{C}$. Although the total dissolution was increased remarkably by increasing temperature from ambient temperature to $100^{\circ} \mathrm{C}$, the NMP dissolution efficiency did not change significantly. For instance, the total dissolution efficiency at first stage increases $77 \%$ by increasing temperature while the NMP dissolution efficiency enhances about $25 \%$. As seen in Table I, the NMP dissolution efficiency increases from 15.7 to $35.1 \%$ by increasing the number of stages to three.

In dissolution experiments with water as a polar solvent, $31.4 \mathrm{wt} \%$ of feed was dissolved containing $65.2 \mathrm{wt} \%$ of total NMP. In comparison to n-heptane, water has a better efficiency and worse selectivity. In order to improve the efficiency and selectivity, the effect of water $\mathrm{pH}$ was investigated. The HPLC chromatograms of filtrate after dissolution in water are illustrated in Fig. 2, and the efficiencies are listed in Table I. As it can be seen, the efficiencies in either basic or acidic conditions are slightly higher than those in neutral conditions. The higher total efficiency corresponds to lower selectivity. In addition, since a foreign compound is required for $\mathrm{pH}$ adjustment in acidic/basic conditions, the neutral dissolution is preferred.
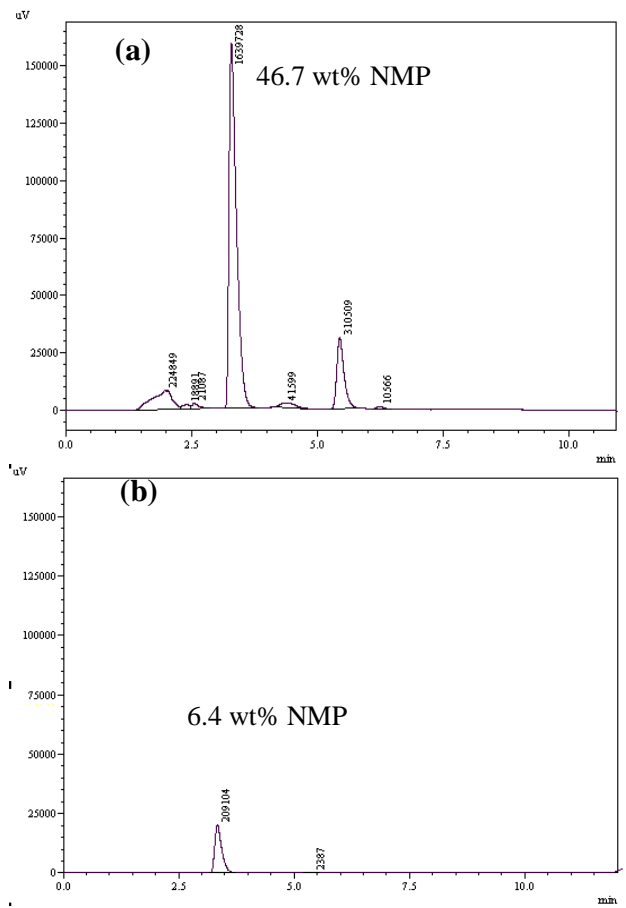

Fig. 1. HPLC chromatograms of (a) feed and (b) filtrate after dissolution in n-heptane.

TABLE I: NMP AND TOTAL DISSOLUTION EFFICIENCIES FOR DIFFERENT SOLVENTS

\begin{tabular}{|c|c|c|c|c|}
\hline Solvent & $\begin{array}{l}\text { Dissolution } \\
\text { conditions }\end{array}$ & Stage No. & $\eta_{\mathrm{N}}(\%)$ & $\begin{array}{c}\eta_{\mathrm{T}} \\
(\%)\end{array}$ \\
\hline Butanol & Ambient temp. & one stage & 100 & 100 \\
\hline Octanol & Ambient temp. & one stage & 85.8 & 76.4 \\
\hline \multirow{7}{*}{ n-Heptane } & \multirow{4}{*}{ Ambient temp. } & $1^{\text {st }}$ stage & 17.6 & 22.0 \\
\hline & & $2^{\text {nd }}$ stage & 13.5 & 9.7 \\
\hline & & $3^{\text {rd }}$ stage & 12.9 & 3.7 \\
\hline & & Overall & 35.1 & 36.5 \\
\hline & \multirow{3}{*}{$100^{\circ} \mathrm{C}$} & $1^{\text {st }}$ stage & 22.1 & 39.1 \\
\hline & & $2^{\text {nd }}$ stage & 23.9 & 38.8 \\
\hline & & Overall & 35.7 & 71.3 \\
\hline \multirow{3}{*}{ Water } & $\begin{array}{c}\text { Neutral, } \\
\text { ambient temp. }\end{array}$ & one stage & 65.0 & 31.4 \\
\hline & $\begin{array}{l}\text { Basic, ambient } \\
\text { temp. }\end{array}$ & one stage & 76.1 & 43.4 \\
\hline & $\begin{array}{l}\text { Acidic, ambient } \\
\text { temp. }\end{array}$ & one stage & 77.8 & 43.5 \\
\hline
\end{tabular}

Although n-heptane has higher selectivity for dissolving NMP than water (Fig. 1), water was selected as the solvent for further experiments because:

- The NMP dissolution efficiency by $n$-heptane in 3 stages is $35.1 \%$ while this value for water in one stage is about $65 \%$.

- $\quad \mathrm{n}$-Heptane is considered as an external compound that should be removed from the recovered NMP. Although it can be separated by distillation, a complete separation is almost impractical. 
- The high volatility of n-heptane increases the environmental hazards and operation difficulties.
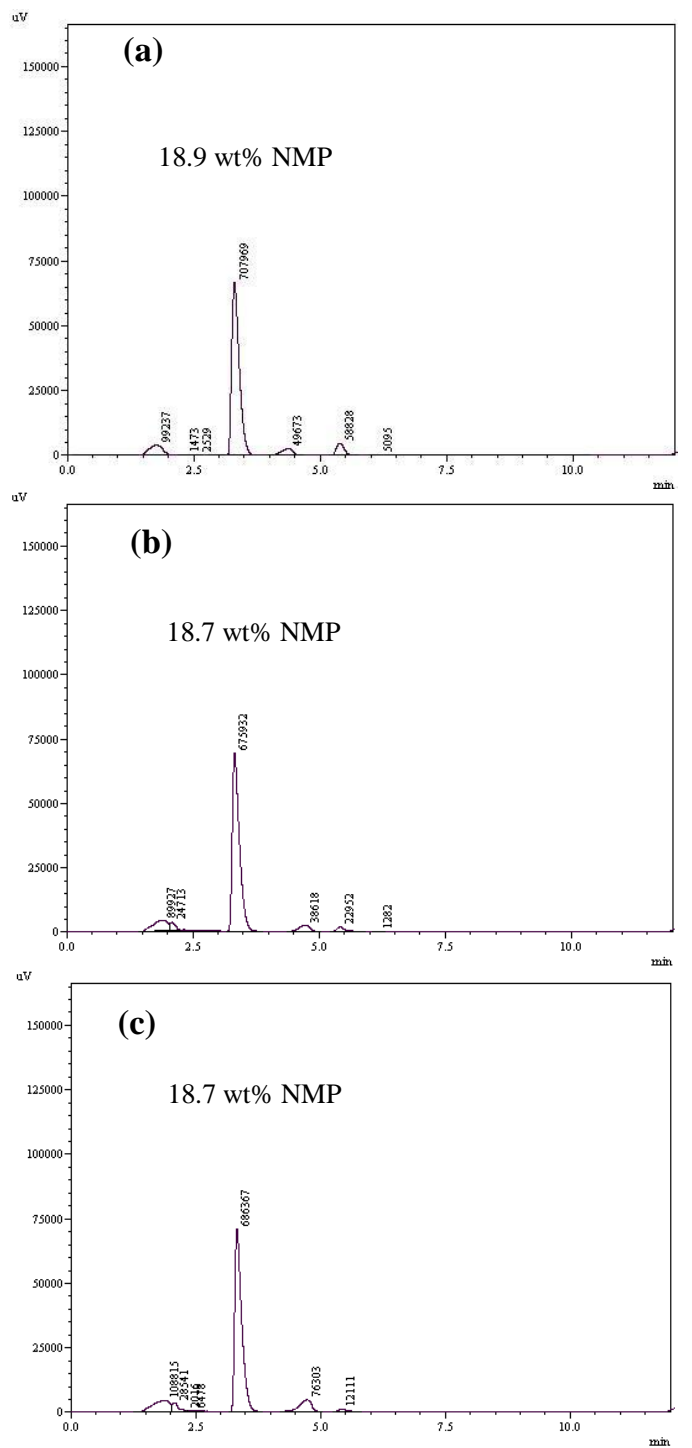

Fig. 2. HPLC chromatograms of filtrates after dissolution in (a) neutral, (b) acidic, and (c) basic water.

\section{B. Coagulation Tests}

Fig. 3 shows the HPLC chromatograms of filtrates after coagulation experiments by different coagulants. As seen in the figure, among the coagulants, $\mathrm{Fe}_{2}\left(\mathrm{SO}_{4}\right)_{3}$ represents the best performance for removal of impurities. The impurities are separated from the solution mainly as scum.

\section{Suggested Process}

Based on the experimental results for NMP recovery and by considering technical and economic aspects, a procedure was adopted for recovering of NMP from waste of solvent recovery unit. The suggested process flow diagram is illustrated in Fig. 4.

According to this process, the waste of solvent regeneration unit of $\mathrm{BD}$ plant is first dissolved in water. In the second step, $\mathrm{Fe}_{2}\left(\mathrm{SO}_{4}\right)_{3}$ is added to the feed solution and agitated. The mixture is allowed to settle. The precipitations and flocs are removed by filtration through strains where the filtrated solid are collected and disposed. The filtrate solution is then conducted to a vacuum distillation column, in which NMP is separated from water and other dissolved impurities.

The HPLC analysis of recovered NMP based on the suggested procedure in lab scale yielded a purified product containing about $93 \mathrm{wt} \% \mathrm{NMP}$ and $7 \mathrm{wt} \%$ water. The product obtained from the above process is suitable to be applied directly in the BD plant.
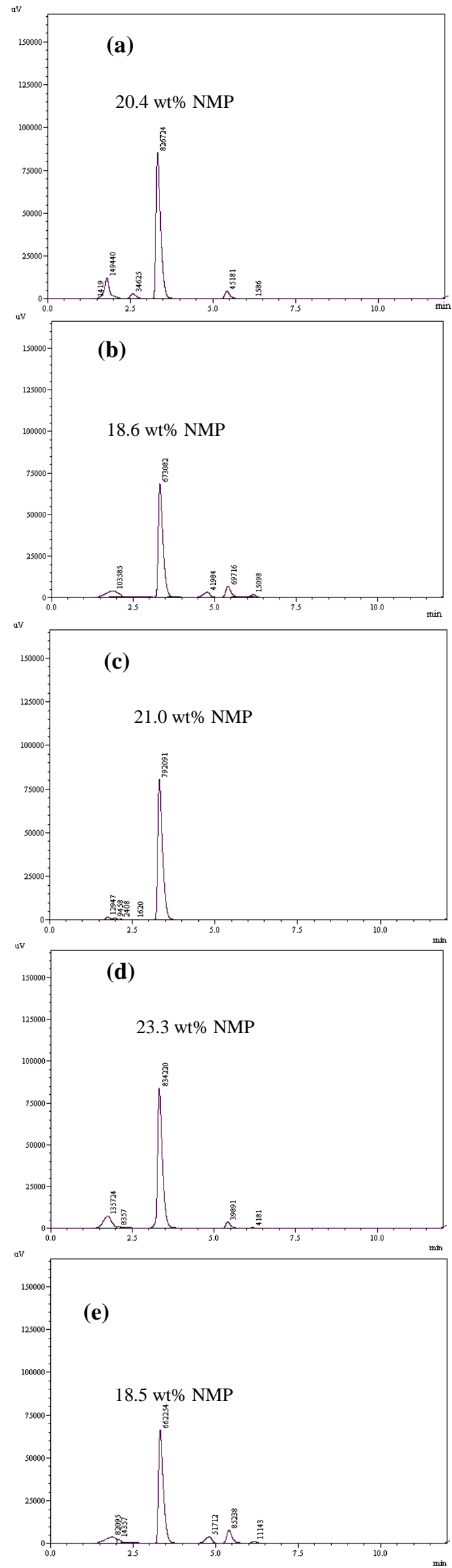

Fig. 3. HPLC chromatograms of filtrates after coagulation experiments by (a) $\mathrm{CaCl} 2$, (b) $\mathrm{Al}(\mathrm{OH}) 3$, (c) $\mathrm{Fe} 2(\mathrm{SO} 4) 3$, (d) $\mathrm{Ca}(\mathrm{OH}) 2$, and (e) PAM coagulants. 


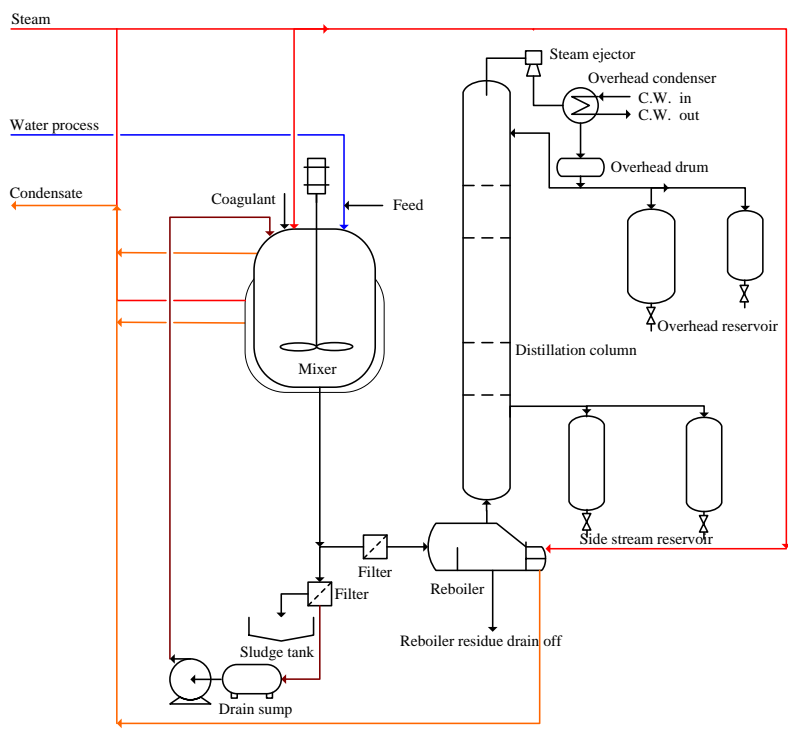

Fig. 4. Suggested flow diagram of NMP recovery process.

\section{CONCLUSION}

NMP was recovered from the waste of NMP regeneration unit in the BD plant by different experiments. Based on the experimental results and considering different aspects, an economic and eco-friendly procedure was suggested comprising water dissolution, coagulation, and vacuum distillation processes. The results obtained from the experiments based on the suggested procedure in a lab scale confirmed that the product is suitable to be applied directly in the BD plant.

\section{ACKNOWLEDGMENT}

The authors would like to acknowledge the research grant by Jam Petrochemical Complex.

\section{REFERENCES}

[1] F. Jalali and R. Saffari, "Simulation and optimization in 1,3-butadiene process from C4-Cut using genetic algorithm," in Proc. $16^{\text {th }}$ European Symposium on Computer Aided Process Engineering, 2006.

[2] W. C. White, "Butadiene production process overview," Chem. Biol. Interact., vol. 166, pp. 10-14, 2007.

[3] Z. Lei, R. Zhou, and Z. Duan, "Process improvement on separating C4 by extractive distillation," Chem. Eng. J., vol. 85, pp. 379-386, 2002.

[4] Z. Lei, C. Li, and B. Chen, "Extractive distillation: A review," Sep. Purif. Rev., vol. 32, pp. 121-213, 2003.

[5] Z. Lei, R. Zhou, and Z. Duan, "Process improvement on separating C4 by extractive distillation," Chem. Eng. J., vol. 85, pp. 379-386, 2002.

[6] C. Ruiz, J. Coca, A. Vega, and F. V. Diez, "Extractive distillation of hydrocarbons with dimethylformamide: experimental and simulation data," Ind. Eng. Chem. Res., vol. 36, pp. 4934-4939, 1997.

[7] A. S. Al-Jimaz, M. S. Fandary, K. H. A. E. Alkhaldi, J. A. Al-Kandary, and M. A. Fahim, "Extraction of aromatics from middle distillate using n-methyl-2-pyrrolidone: Experiment, modeling, and optimization," Ind. Eng. Chem. Res., vol. 46, pp. 5686-5696, 2007.

[8] S. Takao, "DMF can efficiently recover butadiene and isoprene," Oil Gas J., vol. 77, pp. 81-82, 1979 .

[9] P. M. Mathias, J. R. Elliott Jr., and A. Klamt, "Butadiene purification using polar solvents. Analysis of solution nonideality using data and estimation methods," Ind. Eng. Chem. Res., vol. 47, pp. 4996-5004, 2008.

[10] R. A. Meyers, Handbook of Petrochemical Production Processes, $1^{\text {st }}$ Ed., New-York, USA: McGraw-Hill, 2005.

[11] J. V. de Oliveira and A. M. Cohen Uller, "Solubility of pure 1,3 butadiene and methyl propene and their mixtures in pure n-methyl-2-pyrrolidone and in its aqueous solutions," Fluid Phase Equilib., vol. 118, pp. 133-141, 1996.
[12] K. Kindler and H. Puhl, "Method for separating a C4 hydrocarbon mixture," U.S. Patent, 6337 429, B1, 2002.

[13] Y. H. Kim, S. Y. Kim, and B. Lee, "Simulation of 1,3-butadiene extractive distillation process using N-methyl-2-pyrrolidone solvent," Korean J. Chem. Eng., vol. 29, pp. 1493-1499, 2012.

[14] Jam Petrochemical Company (JPC), "1,3-butadien purification process description," National Petrochemical Company, Jam, 2004.

[15] S. S. Wong, T. T. Teng, A. L. Ahmad, A. Zuhairi, and G. Najafpour, "Treatment of pulp and paper mill wastewater by polyacrylamide (PAM) in polymer induced flocculation," J. Hazard. Mater., vol. 35, pp. 378-388, 2006.

[16] M. Muruganandham, S. H. Chen, and J. J. Wu, "Mineralization of N-methyl-2-pyrolidoneby advanced oxidation processes," Sep. Purif. Technol., vol. 55, pp. 360-367, 2007.

[17] M. Sorensen and W. Arlt, Liquid-Liquid Equilibrium Data Collection Binary Systems, Chemistry Data Series, Frankfurt, Germany, Schon \& Wetzel GmbH, 1979.

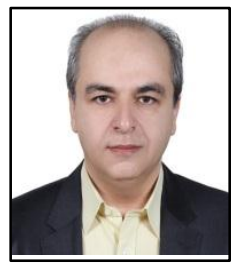

H. R. Mortaheb was born in 1966. He acquired B.Sc. and M.Sc. degree in chemical engineering from Isfahan University of Technology. He received his $\mathrm{Ph} . \mathrm{D}$. in chemical engineering from Tokyo Institute of Technology in 2002. Since then, he has worked in Nippon Refine, Japan. Currently, he is a faculty member in Chemistry and Chemical Engineering Research Center of Iran (CCERI). His emphasis on membrane techniques. research is focused on separation processes with

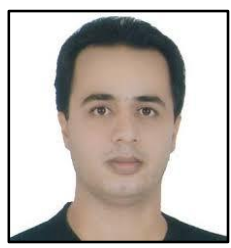

A. Bolhasani was born in 1976. He acquired a B.Sc degree in chemical engineering from Isfahan university of technology, and a M.Sc. degree in chemical engineering from Shiraz University, 2001. $\mathrm{He}$ works as the head of research lab as well as the head of olefin and chemical research in Research and Development of Jam Petrochemical Co. He has of petrochemical units. experienced for about 15 years in different processes

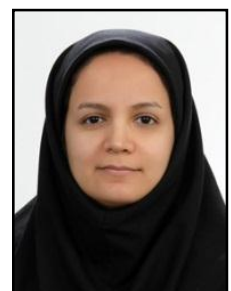

F. Meshkini was born in 1980. She acquired a B.Sc degree in chemical engineering from Iran university of science and technology, and a M.Sc. degree in chemical engineering, process engineering field from Babol Noshirvani university of technology in 2006 She has been working in CCERCI since 2006 and has authored technical papers on separation and treatment topics in international journals.

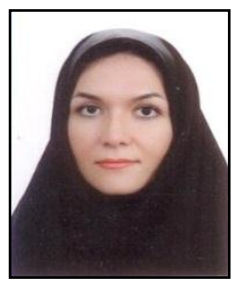

F. Ghaemmaghami was born in 1982. She acquired a B.Sc. degree in chemical engineering, petrochemical industry field from Amirkabir university of technology, Iran, and a M.Sc. degree in chemical engineering, food industry field from Sharif university of technology in 2008. She has been working in CCERCI since 2008 on separation and purification researches. She has publications in international journals.

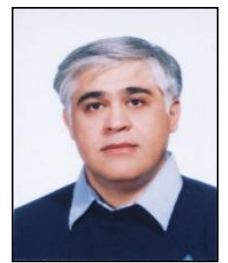

K. Tabar Heidar was born in 1960 . He acquired a B.Sc. degree from Rouen University and both M.Sc and $\mathrm{Ph} . \mathrm{D}$. degrees in analytical chemistry from Claude Bernard University, 1989. He is currently a faculty member in CCERI. His major is on chromatography by GC and HPLC, and mass spectroscopy. 